\title{
Homocysteine Inhibits Hydrogen Peroxide Breakdown by Catalase
}

\author{
Nathaniel G.N. Milton*
}

School of Human and Life Sciences, Whitelands College, Roehampton University, London SW15 4JD, UK

\begin{abstract}
Catalase, an antioxidant enzyme responsible for degradation of hydrogen peroxide, is protective in many diseases. The amino-acid homocysteine has been suggested to be a pro-oxidant with elevated levels linked to the oxidative stress seen in Alzheimer's and other diseases. This study shows that homocysteine inhibits the breakdown of hydrogen peroxide by catalase. Physiological concentrations of homocysteine inhibited catalase breakdown of hydrogen peroxide. The inhibition of catalase was by generation of the inactive catalase compound II and prevented by ethanol or NADPH but unaffected by iron. Physiological concentrations of homocysteine also inhibited cellular catalase but were not cytotoxic. homocysteine enhanced the toxicity of the amyloid- $\beta$ peptide in an in vitro model of Alzheimer's neurodegeneration. The antioxidant vitamin E blocked the toxicity of amyloid- $\beta$ plus homocysteine but not the catalase inhibition. Catalase inhibition by homocysteine may increase the levels of hydrogen peroxide and play a role in the pathology of disease.
\end{abstract}

Keywords: Homocysteine, catalase, compound II, amyloid- $\beta$, Alzheimer's, ethanol, NADPH, iron, vitamin E.

\section{INTRODUCTION}

Hydrogen peroxide $\left(\mathrm{H}_{2} \mathrm{O}_{2}\right)$ is one of the more stable reactive oxygen species and plays a role in the pathologies of many diseases including Alzheimer's disease [1]. Catalase is an antioxidant enzyme found in many cell types and considered to play a major role in the removal of $\mathrm{H}_{2} \mathrm{O}_{2}$ [2-4]. There are over 300 forms of catalase and the enzyme is found in most organisms [5]. Human catalase is a heme protein [6, 7], which also contains an NADPH binding site [8-10]. The structure of human catalase has been determined and the key residues responsible for activity identified $[11,12]$. The active form of human catalase is a tetramer $[2,3,11]$.

Loss of catalase activity is associated with increased susceptibility to oxidative stress $[13,14]$ while over expression studies suggest a role for the enzyme in longevity [15]. A number of compounds have been reported to inhibit the activity of the enzyme including the amino acid cysteine [1619]. The inhibitory actions of cysteine were originally studied with incubations of $\mathrm{mM}$ concentrations of the amino acid with catalase $[2,3,19]$. These conditions are not representative of the physiological levels of this amino acid, which are normally in the $\mu \mathrm{M}$ range, and the observed inhibition is unlikely to occur naturally [20].

Catalase breakdown of $\mathrm{H}_{2} \mathrm{O}_{2}$ causes the formation of compound I $[10,16]$ which can then breakdown either $\mathrm{H}_{2} \mathrm{O}_{2}$ or ethanol. compound I can be converted to an inactive form of catalase, compound II [10, 16], and this inactivation can be prevented by excess ethanol or reversed by NADPH. An alternative model suggests that NADPH prevents formation of compound II [11]; both models are illustrated in Fig. (1). Chemical inhibition of catalase by 3-amino-1,2,4-triazole (3AT) or 3,3'-diaminobenzidine can be prevented by addition of ethanol and NADPH $[10,16]$. Cysteine has been reported

*Address correspondence to this author at the School of Human and Life Sciences, Whitelands College, Roehampton University, Holybourne Avenue London SW15 4JD, UK; E-mail: n.milton@roehampton.ac.uk to inhibit catalase activity by the formation of compound II $[2,3]$.

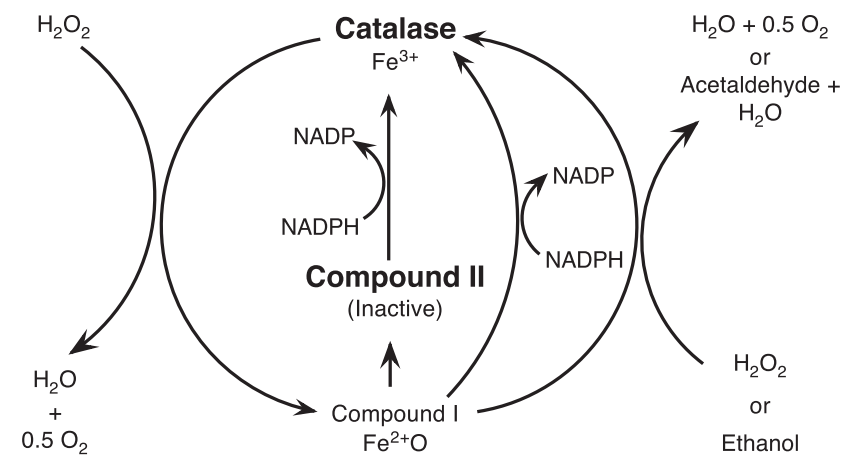

Fig. (1). Schematic representation of the breakdown of $\mathrm{H}_{2} \mathrm{O}_{2}$ and formation of the inactive compound II form of Human catalase.

Homocysteine is a non-essential sulfur-containing amino acid that is derived from methionine metabolism and closely related to cysteine $[21,22]$. homocysteine has been suggested to directly generate $\mathrm{H}_{2} \mathrm{O}_{2}$ [23-25]. Normal blood levels of homocysteine are in the range $5-15 \mu \mathrm{M}$, with around $70 \%$ of this bound to plasma proteins [26]. Within tissues homocysteine is also found in both free and protein bound forms, with similar ratios of bound to free found in most tissues, except the cerebellum which was shown to have high levels of free homocysteine [27]. Cells are able to export homocysteine into the extracellular medium in culture [27]. Elevated homocysteine levels are found in many diseases including Alzheimer's [28], atherosclerosis [29] and type 2 Diabetes [30]. Reduced catalase activity is also a feature of Alzheimer's [31], atherosclerosis [32], and Diabetes [33] raising the possibility of a direct link between elevated homocysteine and reduced catalase activity.

In models of Alzheimer's disease homocysteine enhances the toxicity of the amyloid- $B$ peptide [34-37]. The strong links between homocysteine [38] and neurodegenerative 
disease suggests that these models would be useful to study if homocysteine has any action on catalase. Inhibition of catalase in these cell models increases amyloid- $\beta$ toxicity [18] in a manner similar to that reported for homocysteine enhancement of amyloid- $\beta$ toxicity. The ability of antioxidants, such as vitamin $\mathrm{E}$, to prevent the enhanced toxicity of amyloid- $\beta$ in the presence of homocysteine suggests a role for reactive oxygen species in the process. vitamin $\mathrm{E}$ also blocks the enhanced toxicity of amyloid- $\beta$ in the presence of the catalase inhibitor 3-amino-1,2,4-triazole [18].

In this report the effects of homocysteine on cellular catalase in a neuronal (human SH-SY-5Y) cell line are investigated. The direct effects of homocysteine on Human catalase activity are also investigated. Finally the effects of homocysteine on amyloid- $\beta$ induced toxicity with and without vitamin E protection are investigated in an in vitro model of Alzheimer's disease.

\section{METHODS}

\section{Cell Culture}

The human neuroblastoma SH-SY-5Y cell line was routinely grown in a 1:1 mixture of HAM's F12 and Eagle's minimal essential medium containing $1 \%$ non-essential amino acids and supplemented with $10 \%$ foetal calf serum and antibiotics (penicillin and streptomycin; $1 \%$ each) in a $5 \% \mathrm{CO}_{2}$ humidified incubator at $37^{\circ} \mathrm{C}$. The cells were passaged when confluent and medium was replaced every 2-3 days. Cells were used 4-10 days after plating. Cultures were differentiated for 7 days with $10 \mathrm{mM}$ retinoic acid.

For combined cell viability and intracellular catalase activity experiments $5 \times 10^{4}$ cells were incubated in 24 well dishes in $1 \mathrm{ml}$ medium with test substances for 24 hours. The cells were harvested, an aliquot taken for viability measurement and the remainder precipitated for catalase measurement.

For cytotoxicity experiments $5 \times 10^{3}$ cells were incubated in 96 well dishes in $100 \mu \mathrm{l}$ culture medium and test substances for 24 hours. Cell viability was determined by trypan blue dye exclusion with at least 100 cells counted per well or by MTT reduction [17]. After incubation with test substances MTT (10 $\mu \mathrm{l}: 12 \mathrm{mM}$ stock) was added and cells incubated for a further 4 hours. Cell lysis buffer [100 $\mu \mathrm{l} /$ well; $20 \%(\mathrm{v} / \mathrm{v})$ SDS, $50 \%(\mathrm{v} / \mathrm{v}) \mathrm{N}, \mathrm{N}$-dimethylformamide, $\mathrm{pH}$ 4.7] was added and after repeated pipetting to lyse cells the MTT formazan product formation was determined by measurement of absorbance change at $570 \mathrm{~nm}$. Control levels in the absence of test substances were taken as $100 \%$ and the absorbance in the presence of cells lysed with Triton X-100 at the start of the incubation period with test substances taken as $0 \%$.

\section{Catalase Activity}

Catalase EC 1.11.1.6 from human erythrocytes (Sigma, Dorset, UK) was used for all incubation experiments. Catalase activity of the standard preparation was determined by spectrophotometric measurement of $\mathrm{H}_{2} \mathrm{O}_{2}$ breakdown [39]. For all studies aliquots of this material were used as the standard catalase of known activity.

Activity of catalase $\left(25 \mathrm{kU} \mathrm{l}^{-1}\right)$ incubated with test substances was determined $[17,40]$ after incubation in $60 \mathrm{mM}$ sodium-potassium phosphate buffer at $37^{\circ} \mathrm{C}$ in a total volume of $100 \mu 1$. After incubation catalase activity was determined by mixing $50 \mu \mathrm{l}$ sample with $50 \mu \mathrm{l}$ substrate $(6.5$ $\mu$ mol $\mathrm{H}_{2} \mathrm{O}_{2}$ in phosphate buffer) for 60 secs, adding $100 \mu \mathrm{l}$ of $32.4 \mathrm{mM}$ ammonium molybdate and measurement of absorbance change at $405 \mathrm{~nm}$. Catalase activity was calculated from a standard curve $\left(0-100 \mathrm{kU} \mathrm{l}^{-1}\right)$.

For catalase activity measurements in cell extracts the cell precipitates were washed with PBS, sonicated and protein concentration plus catalase activity of cell lysates determined $[17,18]$.

Sulphur containing amino acids are known to interact with molybdate [41] and tests were carried out check whether the test substances (cysteine, homocysteine and methionine) had any effect on the absorbance change observed at $405 \mathrm{~nm}$ due to the interaction of ammonium molybdate with $\mathrm{H}_{2} \mathrm{O}_{2}$. Results showed no changes in the absorbance in the presence of these amino acids at concentrations up to 500 $\mu \mathrm{M}$. Dilution curves with catalase were also prepared and the effects of adding these amino acids after the addition of the ammonium molybdate to the reaction were also tested, again without any effect at concentrations up to $500 \mu \mathrm{M}$.

\section{Catalase Immunoreactivity}

Catalase standards and cell lysates were diluted in 50 $\mathrm{mM}$ bicarbonate buffer and added to ELISA plates. After overnight incubation and blocking unbound sites with $5 \%$ w/v Marvel the coated plates were incubated with anticatalase antibody (Calbiochem). Bound antibody was de-

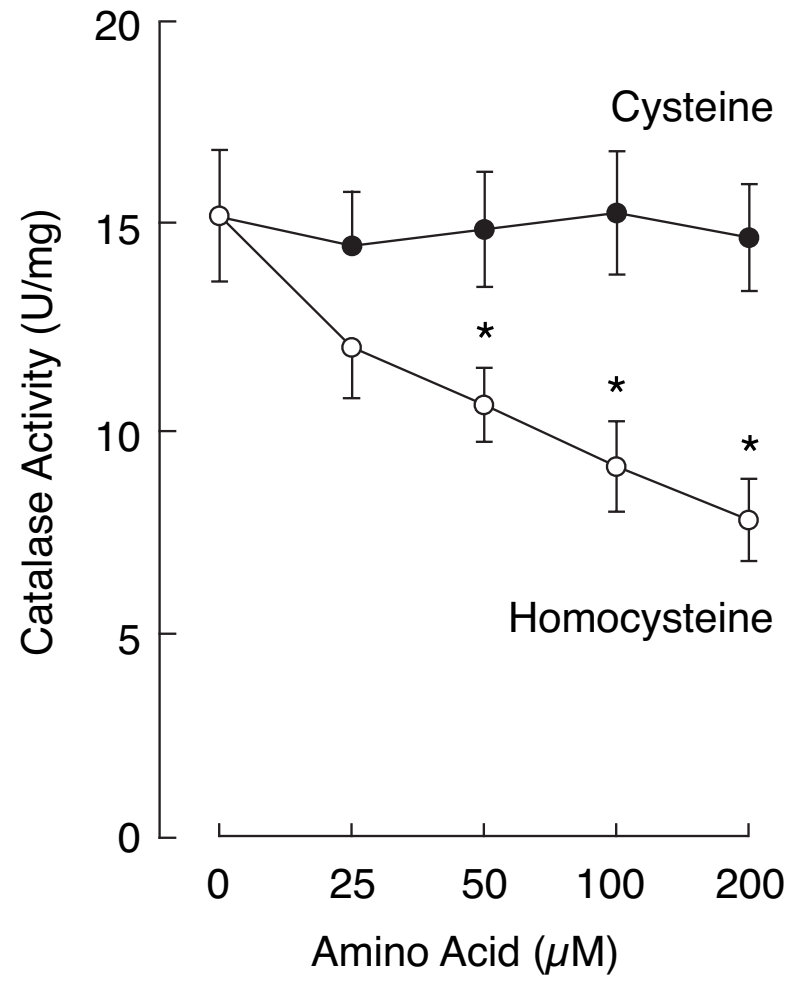

Fig. (2). Effect of homocysteine or Cysteine on the catalase activity. SH-SY-5Y neurons were incubated for 24 hours in the presence of homocysteine (open circles) or cysteine (closed circles). catalase activity was measured in cell lysates and results are expressed as mean $\pm \operatorname{sem}(\mathrm{n}=8) .{ }^{*}=\mathrm{P}<0.05$ vs Control $(0 \mu \mathrm{M}$ amino acid); one-way ANOVA. 
tected using an alkaline phosphatase second antibody plus pnitrophenylphosphate substrate and cell lysate levels determined by interpolation from the standard curve [18].

\section{Data Analysis}

Data are expressed as means \pm sem catalase levels are expressed as \% inhibition of control (untreated) catalase. For cytotoxicity experiments data are expressed as \% dead (trypan blue stained) cells. The significance of differences between data was evaluated by one-way analysis of variance (ANOVA). A P value of $<0.05$ was considered statistically significant [17, 18].

\section{RESULTS}

\section{Effect of Homocysteine on Cellular Catalase Activity}

Homocysteine at concentrations between $25-200 \mu \mathrm{M}$ significantly decreased the cellular catalase activity of $\mathrm{SH}-$ SY-5Y neurons in culture when added for a $24 \mathrm{~h}$ period (Fig. 2). The related amino acids cysteine and methionine had no effect at similar concentrations $(25-200 \mu \mathrm{M})$. The levels of immunoreactive catalase were unchanged by $200 \mu \mathrm{M}$ homocysteine, $200 \mu \mathrm{M}$ cysteine or $200 \mu \mathrm{M}$ methionine when compared to control cells (Fig. 3).

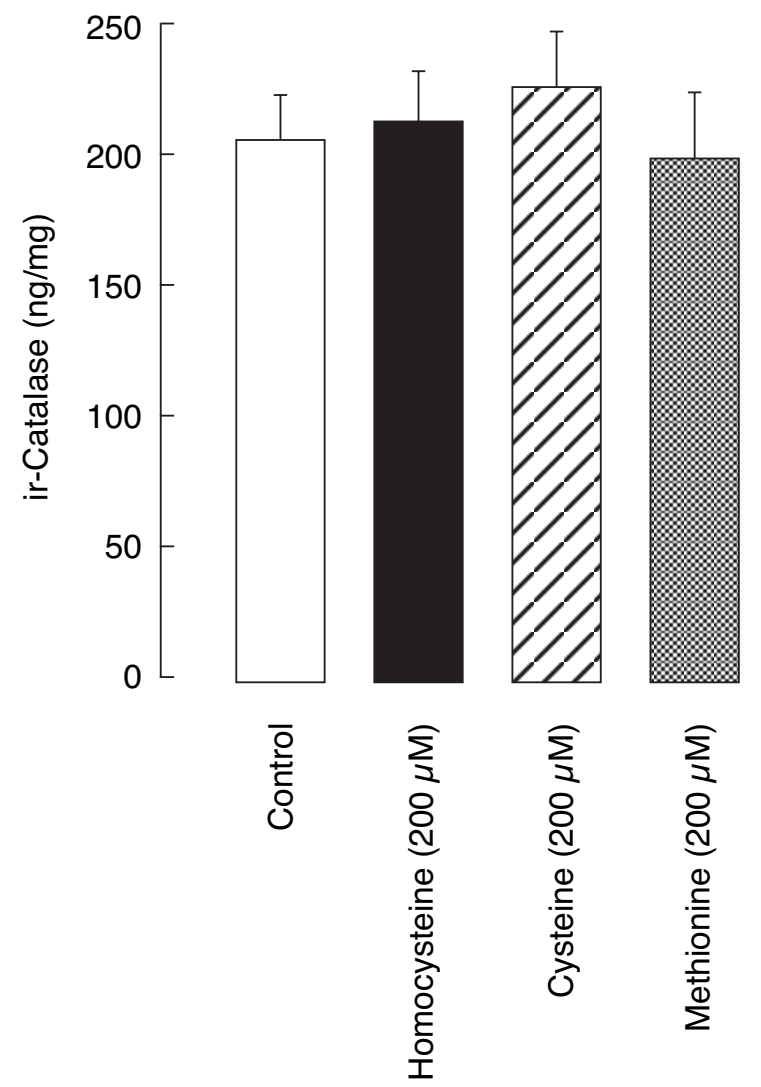

Fig. (3). Effect of homocysteine, Cysteine and Methionine on the catalase levels. SH-SY-5Y neurons were incubated for 24 hours in the presence of homocysteine, cysteine or methionine. catalase immunoreactivity and protein concentrations were measured in cell lysates and results are expressed as mean $\pm \operatorname{sem}(n=8)$.

\section{Effect of Homocysteine on Catalase Breakdown of $\mathrm{H}_{2} \mathrm{O}_{2}$}

The effects of homocysteine plus the related amino acids methionine and cysteine on catalase breakdown of $\mathrm{H}_{2} \mathrm{O}_{2}$ were examined. Incubation of human catalase with homocysteine caused a significant dose dependent inhibition of $\mathrm{H}_{2} \mathrm{O}_{2}$ breakdown (Fig. 4).

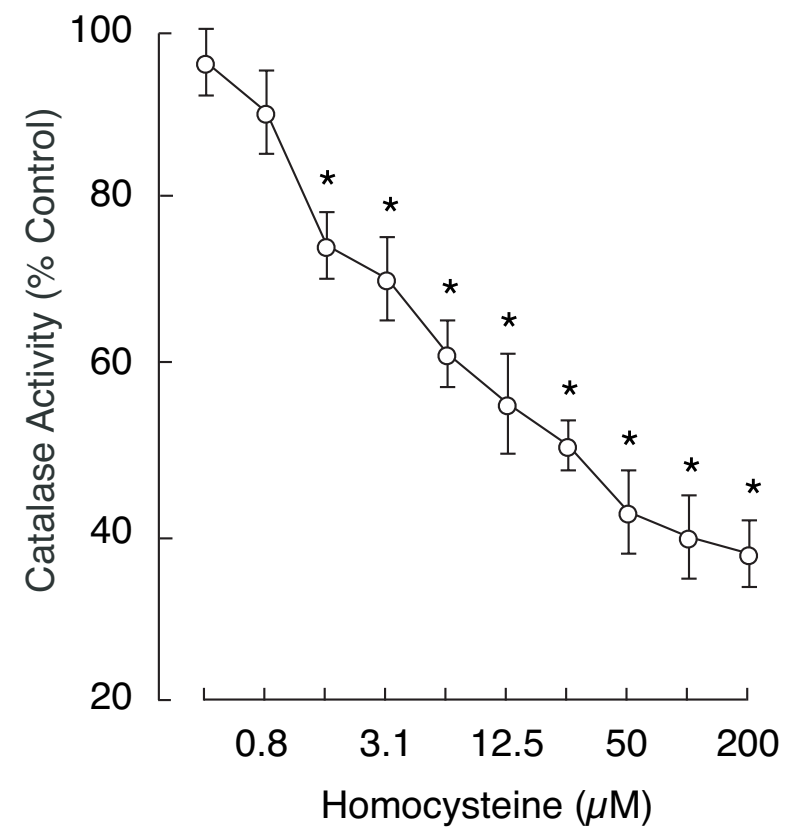

Fig. (4). Effect of homocysteine on the catalase activity. Human catalase $(25 \mathrm{U} / \mathrm{ml})$ was incubated for $45 \mathrm{~min}$ with homocysteine $(0$ $-200 \mu \mathrm{M})$. Catalase activity was then measured and results interpolated from the standard curve. All results are expressed as a \% Control $(25 \mathrm{U} / \mathrm{ml}$ catalase alone) and are expressed as mean \pm sem $(\mathrm{n}=$ $8)$. * $=\mathrm{P}<0.05$ vs Control $(0 \mu \mathrm{M}$ homocysteine $)$; one-way ANOVA.

The inhibition of catalase activity was time dependent with significant levels of inhibition detected after preincubation for $15 \mathrm{~min}$ with homocysteine. Pre-incubation for $30 \mathrm{~min}$ or pre-incubation for $45 \mathrm{~min}$ with homocysteine showed increased levels of catalase inhibition. Preincubation for $1 \mathrm{~h}$ or longer showed similar levels of activity inhibition to that seen for a $45 \mathrm{~min}$ pre-incubation.

In the presence of sub-maximal doses of amyloid- $\beta 25-35$ or 3-amino-1,2,4-triazole the effects of homocysteine were additive. The related amino acids methionine and cysteine had no effect on catalase activity and neither compound had any effect on catalase activity in the presence of the known catalase inhibitors amyloid- $\beta 25-35$ or 3 -amino-1,2,4triazole.

\section{Effects of Ethanol and NADPH on Homocysteine Inhibi- tion of Catalase}

To determine if homocysteine inhibition of catalase was by formation of the inactive compound II, catalase was incubated in the presence of ethanol or NADPH.

Results showed that the inhibition of catalase by homocysteine was significantly reduced in the presence of ethanol $(20 \mathrm{nM})$ plus $\mathrm{H}_{2} \mathrm{O}_{2}(1 \mathrm{mM})$; control incubations with $\mathrm{H}_{2} \mathrm{O}_{2}(1 \mathrm{mM})$ alone had no effect (Fig. 5). Inhibition of catalase by homocysteine was also significantly reduced in the presence of NADPH $(20 \mu \mathrm{M})$, whilst control incubations with NADP $(20 \mu \mathrm{M})$ had no effect (Fig. 6). 


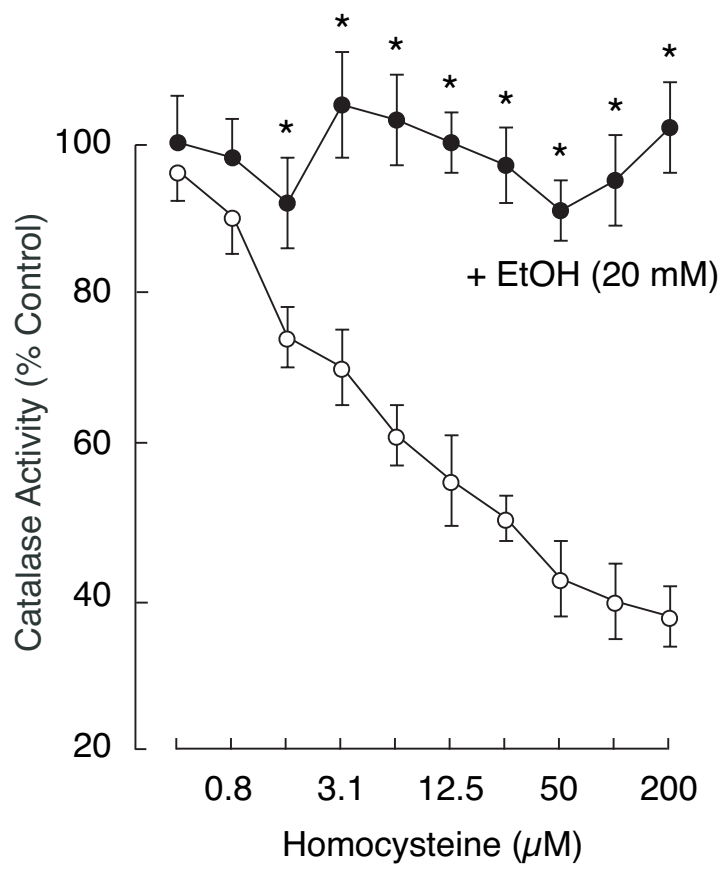

Fig. (5). Effect of ethanol on homocysteine inhibition of catalase activity. Human catalase $(25 \mathrm{U} / \mathrm{ml})$ was incubated for $45 \mathrm{~min}$ with homocysteine $(0-200 \mu \mathrm{M})$ in the presence (closed circles) or absence (open circles) of $20 \mathrm{mM}$ ethanol plus $1 \mathrm{mM} \mathrm{H}_{2} \mathrm{O}_{2}$. Catalase activity was then measured and results interpolated from the standard curve. All results are expressed as a \% Control $(25 \mathrm{U} / \mathrm{ml}$ catalase alone) and are expressed as mean $\pm \operatorname{sem}(\mathrm{n}=8) . *=\mathrm{P}<0.05$ vs Control (homocysteine alone); one-way ANOVA.

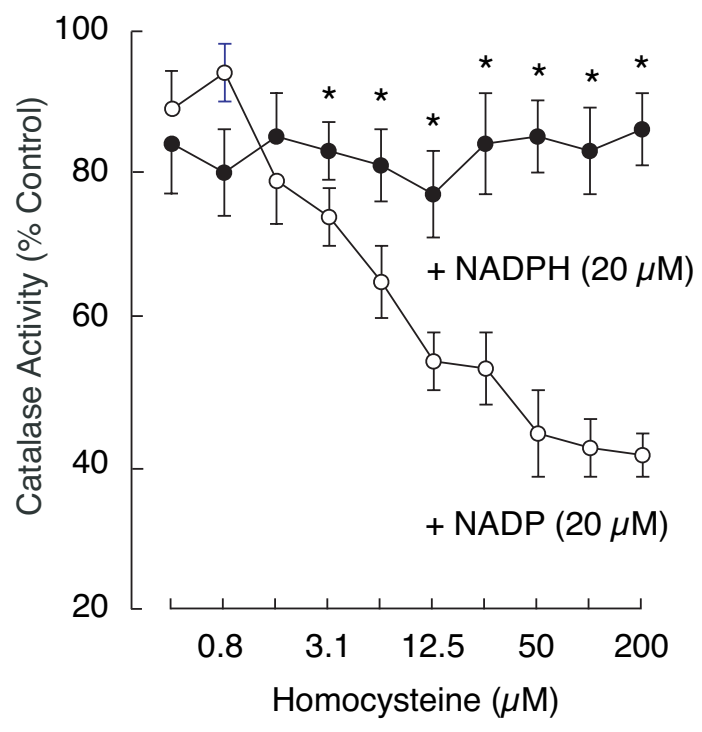

Fig. (6). Effect of NADPH on homocysteine inhibition of catalase activity. Human catalase $(25 \mathrm{U} / \mathrm{ml})$ was incubated for $45 \mathrm{~min}$ with homocysteine $(0-200 \mu \mathrm{M})$ with $20 \mu \mathrm{M}$ NADPH (closed circles) or $20 \mu \mathrm{M}$ NADP (open circles). Catalase activity was then measured and results interpolated from the standard curve. All results are expressed as a \% Control (25 U/ml catalase alone) and are expressed as mean $\pm \operatorname{sem}(\mathrm{n}=8)$. $*=\mathrm{P}<0.05$ vs homocysteine plus NADP; one-way ANOVA.

These results suggest that homocysteine inhibition of catalase activity is mediated by the formation of the inactive compound II form of catalase.

\section{Effects of Iron on Homocysteine Inhibition of Catalase}

Human catalase activity requires iron [11] bound to an active site at residue 358 and it is possible that an interaction between homocysteine and iron could influence enzyme activity.

Incubation of catalase with homocysteine in buffer supplemented with $25 \mu \mathrm{M} \mathrm{FeCl}_{2}$ had no significant effect on the inhibition of catalase activity by homocysteine (Fig. 7). Incubation of catalase with homocysteine in buffer supplemented with of $25 \mu \mathrm{M} \mathrm{MgCl}_{2}$ also failed to alter the catalase inhibition induced by homocysteine. These results suggest that homocysteine interactions with the iron in the heme group of catalase is not the main cause of homocysteine induced catalase inhibition.

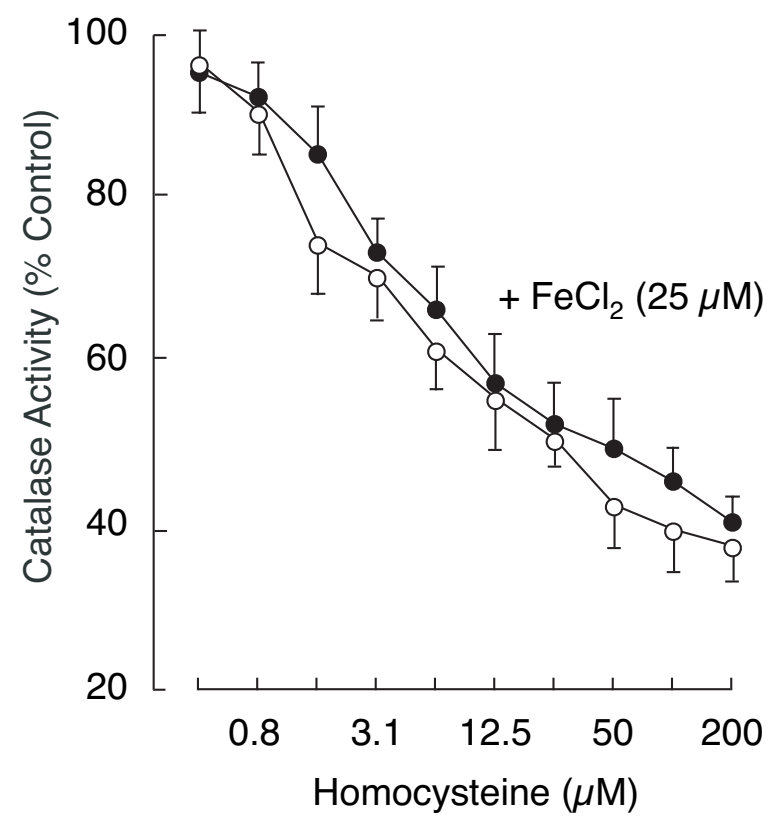

Fig. (7). Effect of $\mathrm{FeCl}_{2}$ on homocysteine inhibition of catalase activity. Human catalase $(25 \mathrm{U} / \mathrm{ml})$ was incubated for $45 \mathrm{~min}$ with homocysteine $(0-200 \mu \mathrm{M})$ in the presence (closed circles) or absence (open circles) of $25 \mu \mathrm{M} \mathrm{FeCl}_{2}$. Catalase activity was then measured and results interpolated from the standard curve. All results are expressed as a $\%$ Control $(25 \mathrm{U} / \mathrm{ml}$ catalase alone) and are expressed as mean $\pm \operatorname{sem}(\mathrm{n}=8)$.

\section{Effect of Homocysteine on an In Vitro Model of Alz- heimer's Neurodegeneration}

Amyloid- $\beta$ toxicity is enhanced by inhibition of catalase activity [18]. Since homocysteine inhibits cellular catalase activity (Fig. 2) it is possible that this amino acid would increase amyloid- $\beta$ toxicity. Cytotoxicity experiments were performed using differentiated human SH-SY-5Y neurons. Cells were incubated with the amyloid- $\beta 1-42$ peptide (2 $\mu \mathrm{M})$ in the presence or absence of homocysteine $(0-200 \mu \mathrm{M})$ for $24 \mathrm{~h}$.

Results showed that in the presence of amyloid- $\beta$ 1-42 (2 $\mu \mathrm{M})$ addition of homocysteine caused a dose dependent decrease in MTT reduction (Fig. 8), with doses of $50 \mu \mathrm{M}$ or greater significantly decreasing the MTT reduction in the presence of amyloid- $\beta$ 1-42. Both amyloid- $\beta 1-42$ and amy- 
loid- $\beta 25-35$ caused a significant increase in the \% cell death. The cytotoxic effects of amyloid- $\beta$ 1-42 were increased in the presence of the homocysteine, which was not itself cytotoxic.

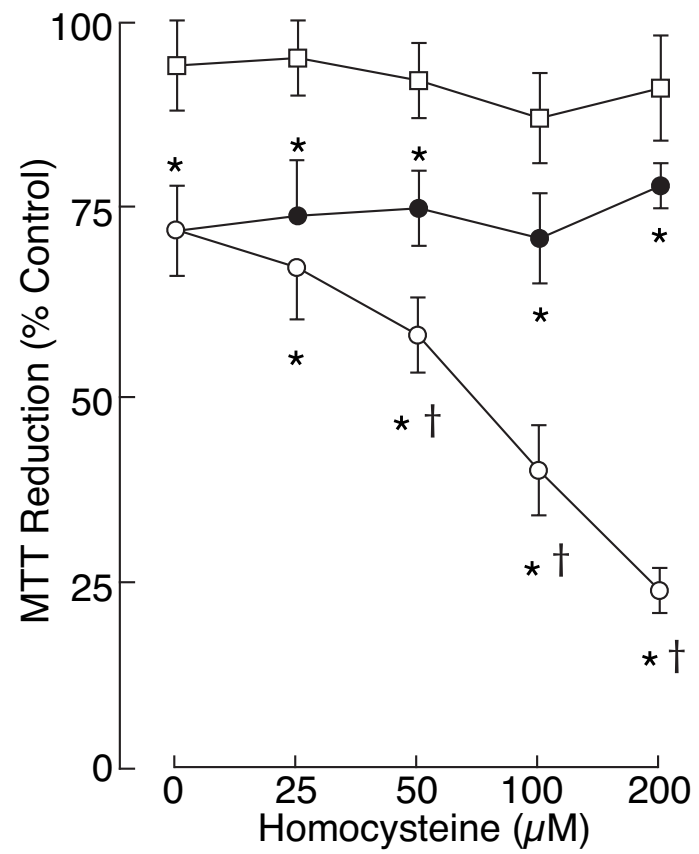

Fig. (8). Effect of homocysteine on MTT Reduction in the presence and absence of amyloid- $\beta$ 1-42. Human amyloid- $\beta$ 1-42 $(2 \mu \mathrm{M})$ with $0-200 \mu \mathrm{M}$ homocysteine (open circles) or alone (closed circles) was added to SH-SY-5Y cells. homocysteine alone (open squares) was also added to SH-SY-5Y cells. MTT reduction was measured after a 24-hour incubation. All results are expressed as a $\%$ Control (SH-SY-5Y cells alone) and are expressed as mean \pm sem $(\mathrm{n}=8)$. * $=\mathrm{P}<0.05$ vs Control $(0 \mu \mathrm{M}$ homocysteine $) ; \dagger=\mathrm{P}<$ 0.05 vs amyloid- $\beta$ alone (closed circles); one-way ANOVA.

\section{Effects of Homocysteine Plus Amyloid-ß on Cellular Catalase Activity}

Since both amyloid- $\beta[17,18]$ and homocysteine cause inhibition of catalase activity cells were incubated with a combination to test the effects. Differentiated human SHSY-5Y neurons were incubated with the amyloid- $\beta$ 1-42 peptide $(2 \mu \mathrm{M})$ in the presence or absence of homocysteine $(0-$ $200 \mu \mathrm{M}$ ) for $24 \mathrm{~h}$. amyloid- $\beta 1-42$ caused a significant reduction in catalase activity. The combination of amyloid- $\beta 1$ 42 and homocysteine also significantly enhanced the reduction in catalase activity compared to homocysteine alone (Fig. 9).

\section{Effects of Vitamin E on Homocysteine Enhanced Neu- rodegeneration In Vitro}

A number of antioxidants protect against amyloid- $\beta$ cytotoxicity [42]. To confirm that the cytotoxicity of amyloid- $\beta$ observed in these studies was mediated by a similar oxidative stress mechanism the effect of vitamin E [43] on human SH-SY-5Y neurons was tested. Results showed that treatment of cells with vitamin E $(100 \mu \mathrm{g} / \mathrm{ml})$ prevented the cytotoxicity of both amyloid- $\beta$ 1-42 and amyloid- $\beta 25-35$. Vitamin E treatment also prevented the cytotoxicity of both amyloid- 3 1-42 and amyloid- $\beta$ 25-35 in the presence of homocysteine (Fig. 10). Confirming that in the presence of homo- cysteine the amyloid- $\beta$ was mediating its cytotoxicity in a similar manner.

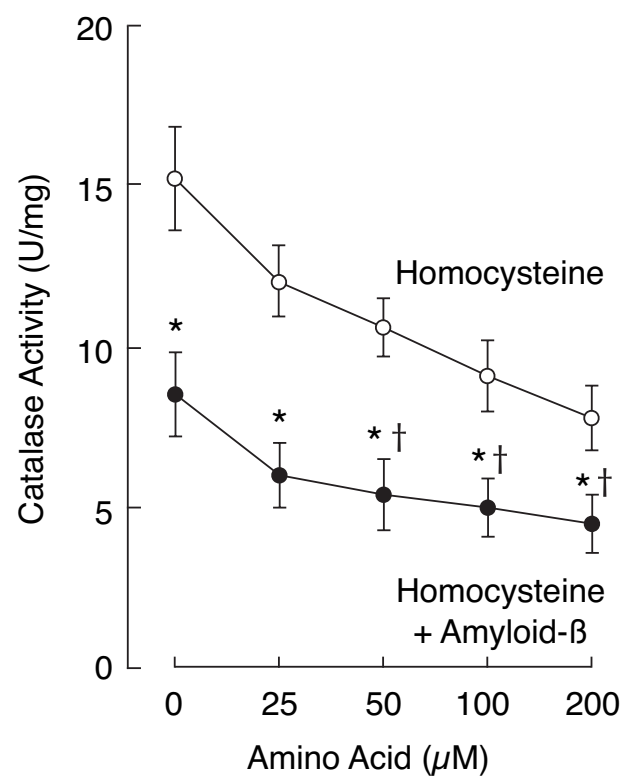

Fig. (9). Effect of homocysteine and amyloid- $\beta$ on the catalase activity. SH-SY-5Y neurons were incubated for 24 hours in the presence of homocysteine (open circles) or homocysteine plus 2 $\mu \mathrm{M}$ amyloid- $\beta$ (closed circles). Catalase activity was measured in cell lysates and results are expressed as mean $\pm \operatorname{sem}(n=8)$. $*=P<$ 0.05 vs Control (homocysteine alone) $\dagger=\mathrm{P}<0.05$ vs amyloid- $\beta$ alone (closed circles); one-way ANOVA.

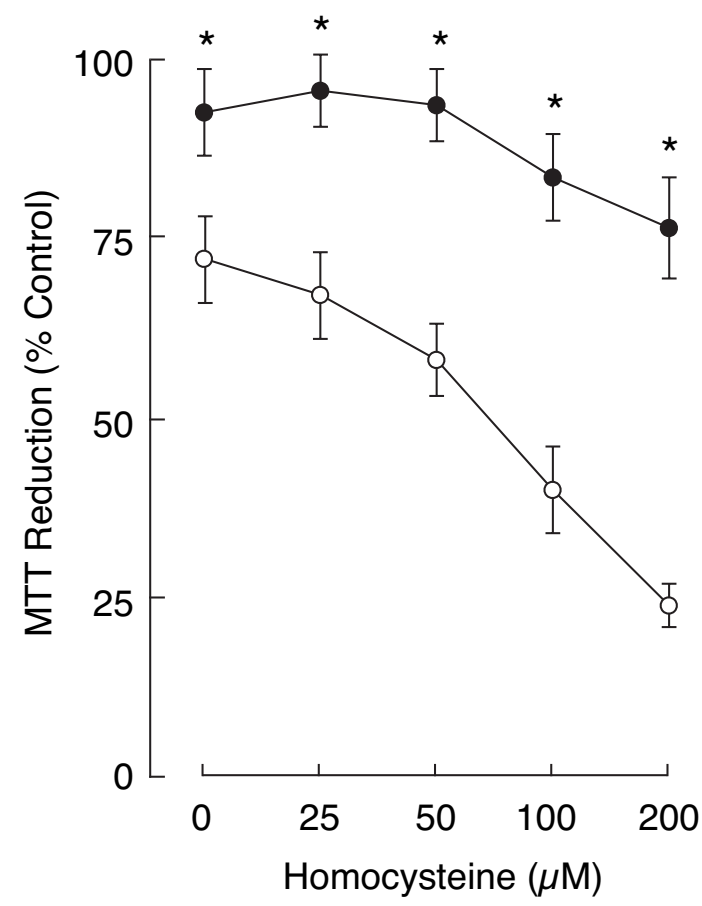

Fig. (10). Effect of vitamin $E$ on the homocysteine enhanced amyloid-\$ 1-42 cytotoxicity. Human amyloid- $\beta$ 1-42 $(2 \mu \mathrm{M})$ plus $0-$ $200 \mu \mathrm{M}$ homocysteine were added to SH-SY-5Y cells with vitamin E (closed circles) or alone (open circles). MTT reduction was measured after a 24-hour incubation. All results are expressed as a $\%$ Control (SH-SY-5Y cells alone) and are expressed as mean \pm sem $(\mathrm{n}=8) . *=\mathrm{P}<0.05$ vs amyloid- $\beta$ plus homocysteine (open circles); one-way ANOVA. 


\section{Effects of Homocysteine Plus Amyloid-ß on Cellular Catalase Activity in the Presence of Vitamin E}

Since both homocysteine and amyloid- $\beta$ inhibit catalase the effects of vitamin $\mathrm{E}$ on this process were tested. Results showed that vitamin $E$ had no effect on the catalase activity itself and was unable to prevent the decreases seen with homocysteine or homocysteine plus amyloid- $\beta$ (Fig. 11). However, there was an increase in catalase inhibition seen in the presence of homocysteine plus amyloid- $\beta$ in the presence of vitamin $\mathrm{E}$, which reached significance at $200 \mu \mathrm{M}$ homocysteine plus $2 \mu \mathrm{M}$ amyloid- $\beta$.

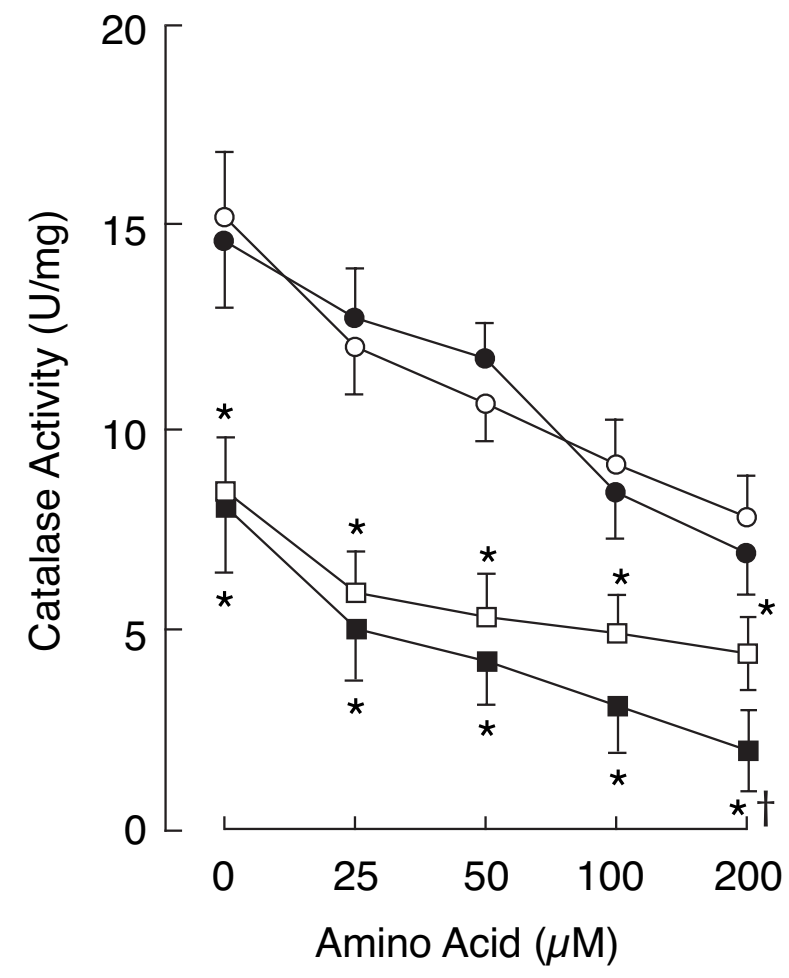

Fig. (11). Effect of vitamin E on homocysteine and amyloid- $\beta$ inhibition of catalase activity. SH-SY-5Y neurons were incubated for 24 hours in the presence of homocysteine alone (open circles), homocysteine plus vitamin E (closed circles), homocysteine plus 2 $\mu \mathrm{M}$ amyloid- $\beta$ (open squares) or homocysteine plus $2 \mu \mathrm{M}$ amyloid$B$ plus vitamin $E$ (closed squares). Catalase activity was measured in cell lysates and results are expressed as mean $\pm \operatorname{sem}(n=8) . *=$ $\mathrm{P}<0.05$ vs Control (homocysteine alone) $\dagger=\mathrm{P}<0.05$ vs homocysteine plus amyloid-ß (open squares); one-way ANOVA.

\section{DISCUSSION}

The results from this study show that homocysteine can directly act on catalase and inhibit the breakdown of $\mathrm{H}_{2} \mathrm{O}_{2}$. The association of homocysteine with disease states in which oxidative stress is a key component of the pathology is undisputed [22, 23, 28-30]. Further there have been considerable studies in which homocysteine has been suggested to directly contribute to the oxidative stress [25, 28, 29, 34-38]. The suggestion that homocysteine can itself generate $\mathrm{H}_{2} \mathrm{O}_{2}$, with the assistance of Copper, has provided a proposed mechanism for this contribution [44-46]. However, at physiological concentrations in the $\mu \mathrm{M}$ range direct generation of $\mathrm{H}_{2} \mathrm{O}_{2}$ by homocysteine is unlikely to be relevant [47].
The mechanism of homocysteine inhibition of catalase is shared with a number of inhibitors including 3-amino-1:2:4:triazole $[11,16]$ and amyloid- $\beta$ [17]. In the case of 3 -amino1:2:4:-triazole the compound has been suggested to interact with a Histidine residue [11] and modify the substrate channel. Both these inhibitors of catalase, 3-amino-1:2:4:-triazole and amyloid- $\beta$, bind to the enzyme $[11,48]$. homocysteine has the ability to bind proteins and to form disulphide bridges with cysteine residues within proteins [49]. Early studies identified 16 cysteines in Human catalase [50], however since catalase is normally a tetramer $[2,3,11]$ this corresponds to 4 cysteines/molecule in agreement with the amino acid sequence of Human catalase [11]. It has been shown that oxidation of the cysteine residues has no effect on the activity of the enzyme [50]. However, thiols such as ß-mercaptoethanol and dithiotreitol have been shown to inhibit catalase activity, raising the possibility that modification of the cysteine residues may alter the enzyme activity. Some of these thiol compounds also modify the heme group of catalase and this may be the cause of the enzyme inactivation [51-53]. In the case of homocysteine the results from the present study show no reversal of the enzyme inhibition in excess $\mathrm{FeCl}$, suggesting that a direct interaction with the Heme Fe is unlikely. This cannot exclude modification of the heme group by other interactions induced by homocysteine.

It is unknown if homocysteine would interact directly with the cysteines present in catalase and which of them would be the potential target if it did. The four cysteines are located in the $\beta 6$ region, two in the wrapping loop between and one in the $\mathrm{C}$-terminal alpha-helical region. None are implicated in the Heme, $\mathrm{H}_{2} \mathrm{O}_{2}$ or NADPH binding in catalase [11]. Further structural studies would be required to determine whether this is the mode of action of homocysteine.

The additive effects of 3-amino-1:2:4:-triazole and amyloid- $\beta$ in terms of induction of cell death have been reported [18]. In this study additive effects of homocysteine and amyloid- $\beta$ were observed. The ability of both to inhibit cellular catalase was observed and the effect was additive. The actions of vitamin $\mathrm{E}$ as an antioxidant and neuroprotective agent are well documented [1, 18, 42, 43] and in this study they prevented the toxicity of amyloid- $\beta$ alone and with homocysteine. The inhibition of catalase by amyloid- $\beta$ [17] was thought to be contributory to the neurotoxicity of the peptide [18] but not causal. The ability of vitamin E to prevent the neurotoxicity of amyloid- $\beta$ but not the effects on catalase indicate that vitamin $\mathrm{E}$ is acting downstream of the inhibitory actions of amyloid- $\beta$ on catalase. The observation that in the presence of vitamin $\mathrm{E}$ there is an additive effect on catalase inhibition and the significant increase in catalase inhibition compared to cells not treated with vitamin $\mathrm{E}$ is an interesting observation. In a previous study [18] amyloid-B inhibited total cellular catalase activity but significantly increased the catalase activity of the surviving cells. In the vitamin E plus amyloid- $\beta$ treated group there was little cell death and therefore the cell population will have included those cells with lower catalase levels which were more susceptible to the toxic effects of amyloid- $\beta$. It is also likely that the inhibition would be more pronounced in cells with lower catalase activity and this may be responsible for the observed effects. 


\section{Why is Homocysteine Inhibition of Catalase Important to Disease Pathology?}

Homocysteine is an amino acid and can be readily taken up by cells [54]. catalase is primarily an intracellular component and its protective actions in many tissues such as neurons are probably mediated by the catalase associated with mitochondria [15]. These two features make it highly likely that under physiological conditions homocysteine and catalase will come into contact and the inhibition of $\mathrm{H}_{2} \mathrm{O}_{2}$ breakdown is likely to occur. Homocysteine has also been shown to effect Glutathione Peroxidase gene expression [55] and to directly inhibit the enzyme at physiological concentrations [56]. It is likely that loss of one of these antioxidant enzymes such as occurs in Acatalasemia, the inherited deficiency of catalase [13], the other $\mathrm{H}_{2} \mathrm{O}_{2}$ enzymes can compensate in part for the loss of their antioxidant partner. Since the combination of catalase and Glutathione Peroxidase activities in many disease states linked to oxidative stress are key to the removal of $\mathrm{H}_{2} \mathrm{O}_{2}$ any inhibition of both enzymes the will prove more deleterious. Inherited deficiencies in catalase are associated with Hyperhomocyteimia [57] and the ability of homocysteine to inhibit Glutathione Peroxidase [56] may further reduce the ability to remove $\mathrm{H}_{2} \mathrm{O}_{2}$ in these individuals. This may explain the observed increased susceptibility of Acatalasemic individuals to diseases associated with oxidative stress such as Diabetes and Atherosclerosis [57]. Hyperhomocysteimia has the potential to dramatically reduce the $\mathrm{H}_{2} \mathrm{O}_{2}$ removal facilities and aggravate oxidative stress.

The strong links between oxidative stress and Neurodegenerative disorders such as Alzheimer's [1] plus the protective role of catalase in these disorders $[18,42,58-60]$ suggests that any endogenous inhibitor of catalase has potential to contribute detrimentally to the disease pathology. Combined with the inhibition of Glutathione Peroxidase activity homocysteine is likely to be a major contributor to Neurodegenerative disorder pathology, which has been linked to oxidative stress in most cases [61].

From the results of this study and the study of Durmaz and Dikmen [56] a new proposed mechanism can be put forward - that homocysteine inhibits the breakdown of $\mathrm{H}_{2} \mathrm{O}_{2}$ and this allows any stimulus for $\mathrm{H}_{2} \mathrm{O}_{2}$ generation to drive oxidative stress.

\section{CONCLUSIONS}

Homocysteine directly inhibits catalase breakdown of $\mathrm{H}_{2} \mathrm{O}_{2}$ by conversion of the enzyme into the inactive compound II form. This action occurs at physiological concentrations and can be observed in cells. The inhibition of catalase may be the mechanism for homocysteine enhancement of amyloid- $\beta$ toxicity in an Alzheimer's disease model. This action of homocysteine, in combination with its ability to inhibit Glutathione Peroxidase, may play a role in oxidative stress and contribute to the pathology of diseases associated with Hyperhomocysteimia.

\section{ACKNOWLEDGEMENTS}

This study was partially supported by a Department of Trade and Industry Grant and NeuroDelta Ltd. I would like to thank L R Francis and Prof J R Harris for support and advice.

\section{REFERENCES}

[1] Milton NGN. Role of hydrogen peroxide in the aetiology of Alzheimer's Disease: implications for treatment. Drugs Aging 2004; 21(2): 81-100.

[2] Deisseroth A, Dounce AL. Catalase: physical and chemical properties, mechanism of catalysis, and physiological role. Physiol Rev 1970; 50(3): 319-75.

[3] Chance B, Sies H, Boveris A. Hydroperoxide metabolism in mammalian organs. Physiol Rev 1979; 59(3): 527-605.

[4] Kirkman HN, Gaetani GF. Mammalian catalase: a venerable enzyme with new mysteries. Trends Biochem Sci 2007; 32(1): 44-50.

[5] Zámocký M, Koller F. Understanding the structure and function of catalases: clues from molecular evolution and in vitro mutagenesis. Prog Biophys Mol Biol 1999; 72(1): 19-66.

[6] Stern KG. The constitution of the prosthetic group of catalase. J Biol Chem 1936; 112(2): 661-9.

[7] Fita I, Rossmann MG. The active center of catalase. J Mol Biol 1985; 185(1): 21-37.

[8] Kirkman HN, Gaetani GF. Catalase: a tetrameric enzyme with four tightly bound molecules of NADPH. Proc Natl Acad Sci USA 1984; 81(14): 4343-7.

[9] Kirkman HN, Galiano S, Gaetani GF. The function of catalasebound NADPH. J Biol Chem 1987; 262(2): 660-6

[10] Hillar A, Nicholls P, Switala J, Loewen PC. NADPH binding and control of catalase compound II formation: comparison of bovine, yeast, and Escherichia coli enzymes. Biochem J 1994; 300(2): 5319.

[11] Putnam CD, Arvai AS, Bourne Y, Tainer JA. Active and inhibited human catalase structures: ligand and NADPH binding and catalytic mechanism. J Mol Biol 2000; 296(1): 295-309.

[12] Safo MK, Musayev FN, Wu SH, Abraham DJ, Ko TP. Structure of tetragonal crystals of human erythrocyte catalase. Acta Crystallogr D Biol Crystallogr 2001; 57(1): 1-7.

[13] Góth L, Rass P, Páy A. Catalase enzyme mutations and their association with diseases. Mol Diagn 2004; 8(3): 141-9.

[14] Ho YS, Xiong Y, Ma W, Spector A, Ho DS. Mice lacking catalase develop normally but show differential sensitivity to oxidant tissue injury. J Biol Chem 2004; 279(31): 32804-12.

[15] Schriner SE, Linford NJ, Martin GM, et al. Extension of murine life span by overexpression of catalase targeted to mitochondria. Science 2005; 308(5730): 1909-11.

[16] Margoliash E, Novogrodsky A. A study of the inhibition of catalase by 3-amino-1:2:4:-triazole. Biochem J 1958; 68(3): 468-75.

[17] Milton NGN. Amyloid- $\beta$ binds catalase with high affinity and inhibits hydrogen peroxide breakdown. Biochem J 1999; 344(2): 293-6.

[18] Milton NGN. Inhibition of catalase activity with 3-amino-triazole enhances the cytotoxicity of the Alzheimer's amyloid- $\beta$ peptide. Neurotoxicology 2001; 22(6): 767-74.

[19] Seabra A, Deutsch HF. Studies on catalase inhibition as related to tumors. J Biol Chem 1955; 214(1): 447-54.

[20] El-Khairy L, Vollset SE, Refsum H, Ueland PM. Predictors of change in plasma total cysteine: longitudinal findings from the Hordaland homocysteine study. Clin Chem 2003; 49(1): 113-20.

[21] Brosnan JT, Brosnan ME. The sulfur-containing amino acids: an overview. J Nutr 2006; 136(6 Suppl): 1636S-40S.

[22] Selhub J. homocysteine metabolism. Annu Rev Nutr 1999; 19: 217-46.

[23] Panganamala RV, Karpen CW, Merola AJ. Peroxide mediated effects of homocysteine on arterial prostacyclin synthesis. Prostaglandins Leukot Med 1986; 22(3): 349-56.

[24] Starkebaum G, Harlan JM. Endothelial cell injury due to coppercatalyzed hydrogen peroxide generation from homocysteine. J Clin Invest 1986; 77(4): 1370-6.

[25] Alvarez-Maqueda M, El Bekay R, Monteseirín J, et al. homocysteine enhances superoxide anion release and NADPH oxidase assembly by human neutrophils. Effects on MAPK activation and neutrophil migration. Atherosclerosis 2004; 172(2): 229-38.

[26] Ueland PM, Refsum H, Stabler SP, Malinow MR, Andersson A, Allen RH. Total homocysteine in plasma or serum: methods and clinical applications. Clin Chem 1993; 39(9): 1764-79.

[27] Svardal A, Refsum H, Ueland PM. Determination of in vivo protein binding of homocysteine and its relation to free homocysteine in the liver and other tissues of the rat. J Biol Chem 1986; 261(7): 3156-63. 
[28] Morris MS. homocysteine and Alzheimer's disease. Lancet Neurol $2003 ; 2(7): 425-8$.

[29] Guthikonda S, Haynes WG. homocysteine: role and implications in atherosclerosis. Curr Atheroscler Rep 2006; 8(2): 100-6.

[30] Huijberts MS, Becker A, Stehouwer CD. homocysteine and vascular disease in diabetes: a double hit? Clin Chem Lab Med 2005; 43(10): 993-1000.

[31] Omar RA, Chyan YJ, Andorn AC, Poeggeler B, Robakis NK, Pappolla MA. Increased Expression but Reduced Activity of Antioxidant Enzymes in Alzheimer's Disease. J Alzheimers Dis 1999; 1(3): 139-45.

[32] Leopold JA, Loscalzo J. Oxidative enzymopathies and vascular disease. Arterioscler Thromb Vasc Biol 2005; 25(7): 1332-40.

[33] Góth L, Lenkey A , Bigler WN. Blood catalase deficiency and diabetes in Hungary. Diabetes Care 2001; 24(10): 1839-40.

[34] Kruman II, Kumaravel TS, Lohani A, et al. Folic acid deficiency and homocysteine impair DNA repair in hippocampal neurons and sensitize them to amyloid toxicity in experimental models of Alzheimer's disease. J Neurosci 2002; 22(5): 1752-62.

[35] Ho PI, Collins SC, Dhitavat S, et al. homocysteine potentiates betaamyloid neurotoxicity: role of oxidative stress. J Neurochem 2001; 78(2): 249-53.

[36] Mok SS, Turner BJ, Beyreuther K, Masters CL, Barrow CJ, Small $\mathrm{DH}$. Toxicity of substrate-bound amyloid peptides on vascular smooth muscle cells is enhanced by homocysteine. Eur J Biochem 2002; 269(12): 3014-22.

[37] Hasegawa T, Ukai W, Jo DG, et al. Homocysteic acid induces intraneuronal accumulation of neurotoxic Abeta42: implications for the pathogenesis of Alzheimer's disease. J Neurosci Res 2005; 80(6): 869-76

[38] Obeid R, Herrmann W. Mechanisms of homocysteine neurotoxicity in neurodegenerative diseases with special reference to dementia. FEBS Lett 2006; 580(13): 2994-3005.

[39] Beers RF Jr, Sizer IW. A spectrophotometric method for measuring the breakdown of hydrogen peroxide by catalase. J Biol Chem 1952; 195(1): 133-40.

[40] Góth L. A simple method for determination of serum catalase activity and revision of reference range. Clin Chim Acta 1991; 196(23): 143-51.

[41] Meshinchi S, Matić G, Hutchison KA, Pratt WB. Selective molybdate-directed covalent modification of sulfhydryl groups in the steroid-binding versus the DNA-binding domain of the glucocorticoid receptor. J Biol Chem 1990; 265(20): 11643-9.

[42] Behl C, Davies JB, Lesley R, Schubert D. Hydrogen peroxide mediates amyloid beta protein toxicity. Cell 1994; 77: 817-27.

[43] Behl C, Davies J, Cole GM, Schubert D. Vitamin E protects nerve cells from amyloid-ß-protein toxicity. Biochem Biophys Res Commun 1992; 186: 944-50.

[44] Starkebaum G, Harlan JM. Endothelial cell injury due to coppercatalyzed hydrogen peroxide generation from homocysteine. J Clin Invest 1986; 77(4): 1370-6.

[45] White AR, Huang X, Jobling MF, et al. homocysteine potentiates copper- and amyloid beta peptide-mediated toxicity in primary neu- ronal cultures: possible risk factors in the Alzheimer's-type neurodegenerative pathways. J Neurochem 2001; 76(5): 1509-20.

[46] White AR, Barnham KJ, Huang X, et al. Iron inhibits neurotoxicity induced by trace copper and biological reductants. J Biol Inorg Chem 2004; 9(3): 269-80.

[47] Zappacosta B, Mordente A, Persichilli S, et al. Is homocysteine a pro-oxidant? Free Radic Res 2001; 35(5): 499-505.

[48] Milton NG, Mayor NP, Rawlinson J. Identification of amyloid-beta binding sites using an antisense peptide approach. Neuroreport 2001; 12(11): 2561-6.

[49] Majors AK, Sengupta S, Willard B, Kinter MT, Pyeritz RE, Jacobsen DW. homocysteine binds to human plasma fibronectin and inhibits its interaction with fibrin. Arterioscler Thromb Vasc Biol 2002; 22(8): 1354-9.

[50] Mörikofer-Zwez S, Cantz M, Kaufmann H, von Wartburg JP, Aebi H. Heterogeneity of erythrocyte catalase. Correlations between sulfhydryl group content, chromatographic and electrophoretic properties. Eur J Biochem 1969; 11(1): 49-57.

[51] Miyahara T, Takeda A, Hachimori A, Samejima T. On the heterogeneity of catalase from goat liver. Purification and characterization. J Biochem 1978; 84(5): 1267-76.

[52] Takeda A, Miyahara T, Hachimori A, Samejima T. The interactions of thiol compounds with porcine erythrocyte catalase. J Biochem 1980; 87(2): 429-39.

[53] Aydemir T, Kuru K. Purification and partial characterization of catalase from chicken erythrocytes and the effect of various inhibitors on enzyme activity. Turk J Chem 2003; 27: 85-97.

[54] Cox DW, Watkins JC. Stereoselective uptake of L-homocysteate by rat brain slices. Br J Pharmacol 1976; 57(3): 433P-4P.

[55] Lubos E, Loscalzo J, Handy DE. homocysteine and glutathione peroxidase-1. Antioxid Redox Signal 2007; 9(11): 1923-40.

[56] Durmaz A, Dikmen N. Homocysteine effects on cellular glutathione peroxidase (GPx-1) activity under in vitro conditions. J Enzyme Inhib Med Chem 2007; 22(6): 733-8.

[57] Góth L, Vitai M. The effects of hydrogen peroxide promoted by homocysteine and inherited catalase deficiency on human hypocatalasemic patients. Free Radic Biol Med 2003; 35(8): 882-8.

[58] Goodman Y, Steiner M, Steiner S, Mattson MP. Nordihydroguaiaretic acid protects hippocampal neurons against amyloid bpeptide toxicity, and attenuates free radical and calcium accumulation. Brain Res 1994; 654(1): 171-6.

[59] Manelli AM, Puttfarcken PS. B-amyloid-induced toxicity in rat hippocampal cells: in vitro evidence for the involvement of free radicals. Brain Res Bull 1995; 38(6): 569-76.

[60] Zhang Z, Rydel RE, Drzewiecki GJ, et al. Amyloid B-mediated oxidative and metabolic stress in rat cortical neurons: no direct evidence for a role for $\mathrm{H} 2 \mathrm{O} 2$ generation. J Neurochem 1996; 67(4): 1595-606.

[61] Mattson MP, Pedersen WA, Duan W, Culmsee C, Camandola S. Cellular and molecular mechanisms underlying perturbed energy metabolism and neuronal degeneration in Alzheimer's and Parkinson's diseases. Ann N Y Acad Sci 1999; 893: 154-75. 